\title{
PENGARUH POSISI FILAMEN LYCRA PADA PROSES PEMBUATAN BENANG ELASTAN CMSY 10/40 D SEBAGAI USAHA TERHADAP KEKUATAN TARIK DAN MULUR BENANG DI MESIN RING SPINNING DENGAN ALAT TAMBAHAN V-GROOVE
}

\author{
Oleh : \\ Dimas Kusumaatmadja, Syarif Iskandar dan Nandang Setiawan \\ Staf Pengajar Sekolah Tinggi Teknologi Tekstil
}

\begin{abstract}
On the process of the making of core spun yarn, in this case using a elastan yarn (lycra), there are differentiation spinning method related in conventional regular method (main function; drafting, twisting and winding), for processing core spun yarn there are additional attached part which is function is feedattaching the core yarn (filament-lycra) known as a attached $v$ groove.

The lycra is feed in to the front roll (draft function), which is set by thye velocity of the roll related to the drafting setting, and set the position of the lycra (various scale in attached part), the cotton is covering the lycra (core yarn) by the function of twisting in ring frame.

By the time, processing of covering core spun yarn has an influenced with the properties of the yarn. The main purpose is by comparing three kind various lycra (core yarn) position by cotton as a cover fibre, in core spun yarn; position (1) is on the side position, position (2) is on the centre position, position (3) is between position (1) and (2).
\end{abstract}

\section{INTISARI}

Dalam proses pembuatan benang inti elastan (lycra) khususnya pada mesin ring frame, terdapat perbedaan perlakuan dibandingkan dengan pemintalan jenis lainya. Secara umum terdapat tiga fungsi pada mesin ring frame yaitu; peregangan, pemberi antihan dan penggulungan. Penambahan alat $v$ groove pada mesin ring frame mempunyai fungsi sebagai penghantar filamen, dalam tegangan dan kecepatan tertentu, kepada mulut rol peregang bagian depan. Pada alat tersebut didapat berbagai macam setting posisi untuk menghasilkan benang dengan kualitas tertentu.Filamen lycra dihantarkan terhadap mulut rol peregang bagian depan dimana terjadi peregangan, dan diteruskan ke proses selanjutnya yaitu proses penggintiran antara filamen lycra sebagai benang inti dan roving dengan bahan baku serat kapas sebagai pembungkus luar dari benang tersebut, percobaan terhadap posisi filament, posisi 1 (pinggir), posisi 2 (tengah) dan posisi 3 (diantaranya) yang mempunyai pengaruh pada pembuatan benang elastan terhadap kekuatan dan mulur benang. 


\section{PENDAHULUAN}

Pada proses pembuatan benang elastan terjadi penggabungan dua serat yang berbeda yaitu serat buatan (filamen lycra) dan serat alami yaitu serat kapas. Filamen lycra pada proses ini dapat disebut juga sebagai benang inti, dan serat alami (serat kapas) sendiri disebut juga sebagai serat pembungkus. Proses pembungkusan benang inti didapat pada proses antara peregangan dan penggintiran, dimana kedua serat tersebut tergabung menjadi satu dalam proses peregangan dan penggintiran. Sehingga menghasilkan benang elastan CmSy 10/40 D (Combed Single Yarn dengan Ne. combed 10, dan Td), pada departemen spining $\mathrm{V}$ pada PT Apac Inti Corpora, yang dalam hal ini merupakan produk unggulan PT Apac Inti Corpora, dengan menggunakan mesin ring spinning merk Shanghai FA-503 dengan alat tambahan rol penghantar filament (lycra) $v$ groove merk Pinter SA. Penulis dalam hal ini mencoba untuk melakukan pengamatan terhadap pengaruh posisi, dalam percobaannya berusaha untuk menampilkan berbagai macam perbandingan posisi $(1,2,3)$, dengan harapan dapat mengetahui efek yang didapat terhadap benang dari segi mulur, kekuatan tarik.

Pengamatan dilakukan pada benang hasil dari ring frame yang memproduksi benang combed-lycra 10/40.

Pengujian mutu yang dilakukan antara lain :

1. Uji Nomor benang.

2. Uji Tpi.

3. Uji mulur benang.

4. Uji gaya putus benang.

5. Uji kekuatan tarik benang.

6. Pengamatan efek bungkus kapas.

\subsection{Tinjauan Proses Pemintalan Benang Inti (core spun yarn)}

Teknologi pemintalan benang elastan sistem pelilitan elastomer, elastomer diulur kebawah melalui let-off roller (1) dan rol pengantar (4) menuju rol bagian depan (5) dari unit rollers draft (6). Dalam waktu yang bersamaan benang roving dari bobbin roving (8) ditarik menuju unit rollers draft (6), pada unit rollers draft ini benang roving mengalami tarikan dan terjadi pengecilan diameter benang roving maupun jumlah serat sampai menuju rol depan untuk selanjutnya diberi antihan bersama sama dengan elastomer sehingga benang roving akan melilit pada elastomer menjadi benang elastan (Gambar 2.1) untuk selanjutnya digulung pada spindel (9). (Lihat Gambar 2.2) 


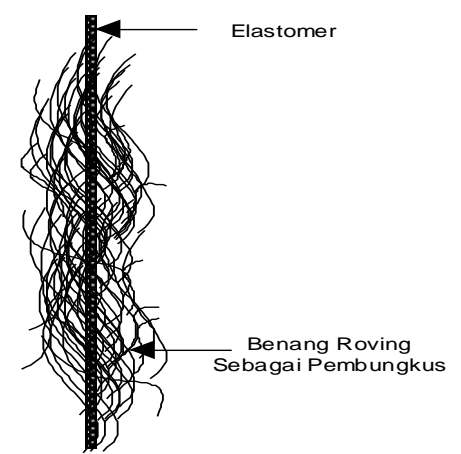

Gambar 1.1 Benang Elastan Terbungkus Roving

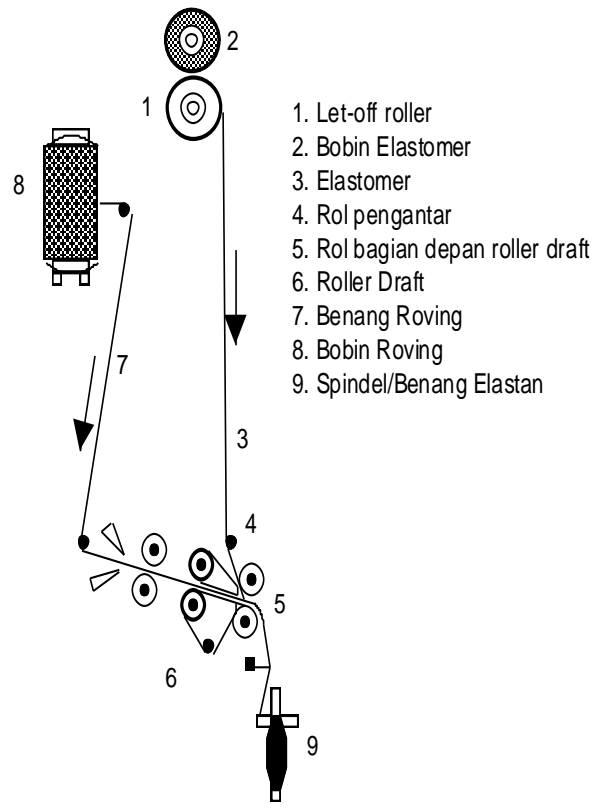

Gambar 1.2 Pemintalan Benang Elastan Dengan Staple Roving

\subsection{Tinjauan Rol Penghantar}

Pada proses pembuatan benang elastan kali ini yang dibahas adalah pembuatan benang elastan dengan metode [1] dimana sesuai dengan penggolongannya didapat pada metode ini menitik beratkan pada proses dimana roving membungkus filamen, setelah melewati rol depan, menuju antihan, dan menuju proses penggulungan.

Dapat digambarkan pada proses berikut dimana rol penghantar, dengan bahasa umum $v$ groove.

Adapun mekanisme $v$ groove dengan merk Pinter SA adalah sebagai berikut : 


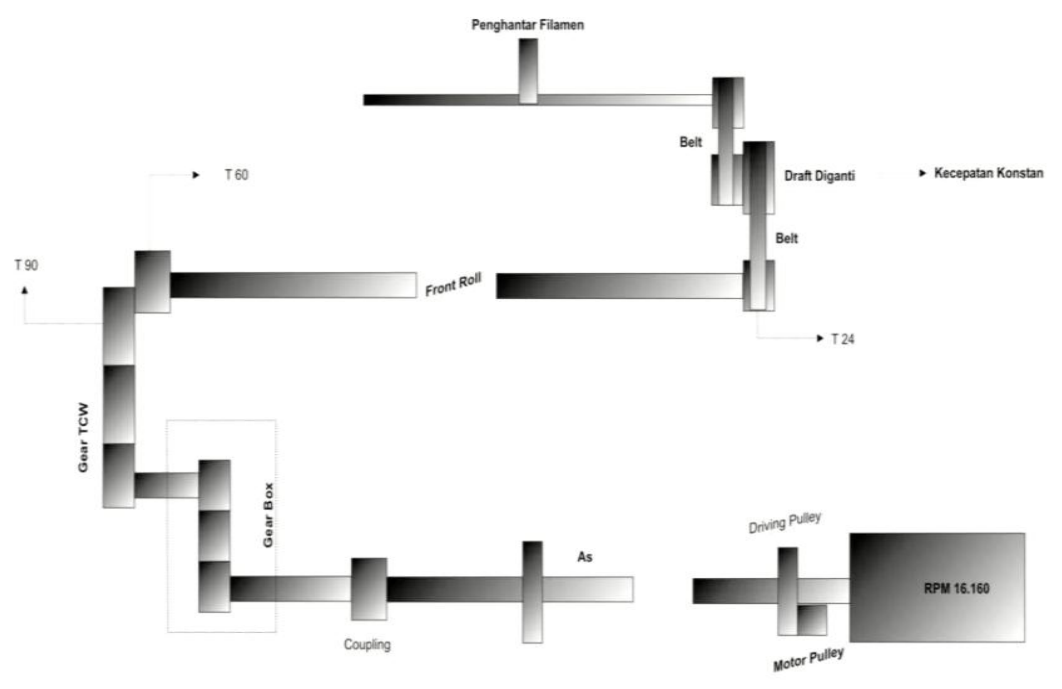

Gambar 1.3 Mekanisme Pergerakan Penghantar Filamen Pinter

Dimana pada gambar tersebut dapat kita lihat bahwa ;

Motor pada mesin ring frame menggerakan motor pulley, driving pulley, as, gear box, gear TCW, melalui roda gigi $(\mathrm{T} 90, \mathrm{~T} 60)$, front roll, lalu terakhir belt, menggerakan penghantar filamen dengan kecepatan konstan (sesuai dengan draft yang dipasang), untuk menyuapkanya pada top front roll.

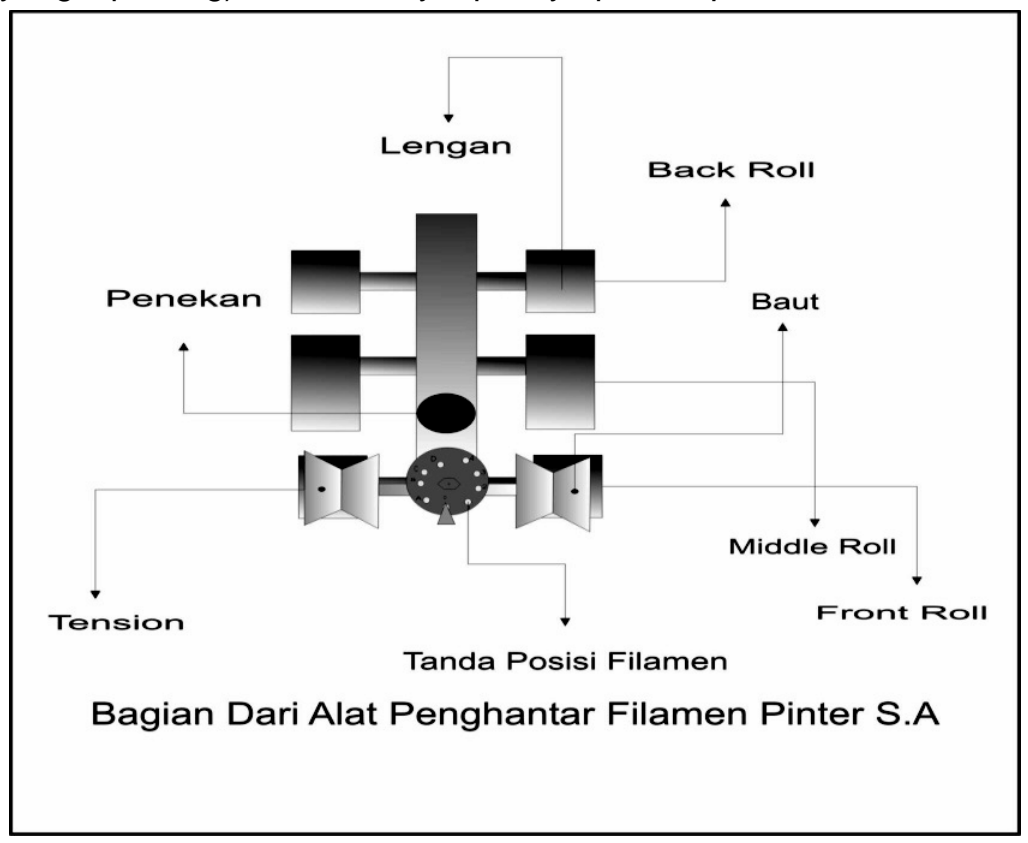

Gambar 1.4 Bagian Arm Tension Pada Pinter Sa 
Bagian yang secara umum disebut $v$ groove, sebagaimana gambar 2.8 diatas dapat kita lihat, bahwa bagian alat tambahan yang terdapat pada arm , khususnya terdapat pada bagian top front roll.

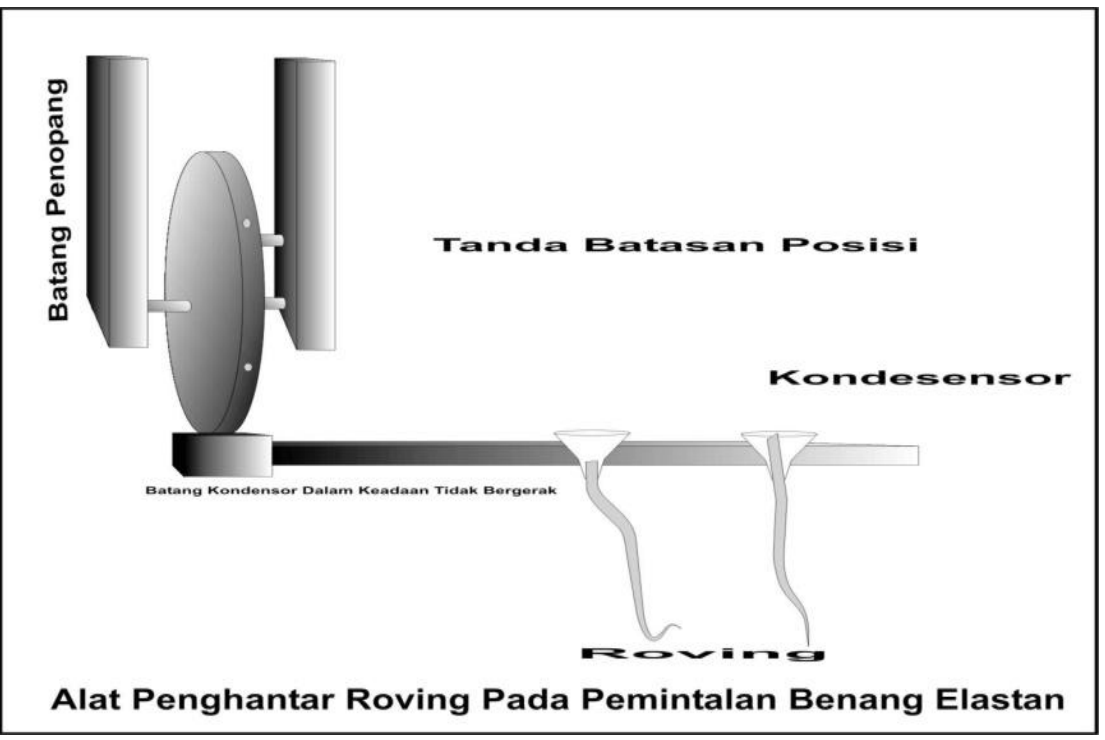

Gambar 1.5 Penghantar Roving Pada Benang Elastan

Selain itu pada pembuatan benang elastan ini, untuk penyuapan roving juga di setting sedemikian rupa agar dapat tepat menyatu dengan filamen tersebut. Fungsi kondensor sendiri pada pemintalan ini tidak mengalami pergesaran, sehingga resiko rubber pada top front roll sangat rentan untuk rusak karena sayatan, akibat friksi dari kedua serat tersebut.

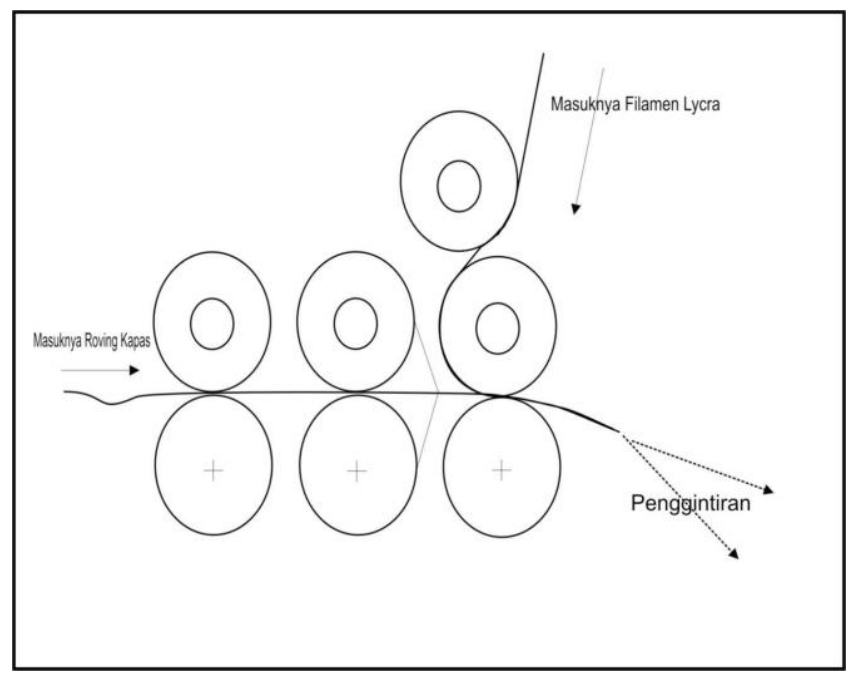

Gambar 1.6 Proses Penggabungan Combed-Lycra 
Pada gambar di atas dapat dilihat bagaimana proses penggabungan dua jenis serat, jatuhnya filamen lycra yang dihantarkan oleh alat tambahan Pinter SA , filamen tersebut dihantarkan pada top front roll, yang kemudian roving kapas yang telah mengalami peregangan pada; back roll dan middle rol menyatu pada front rol.

\subsection{Pembukusan Serat Kapas Pada Filamen Lycra Terhadap Kekuatan Benang}

1. POSISI 1

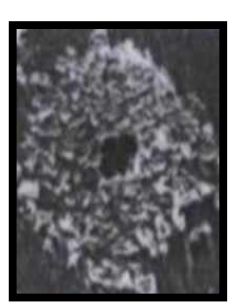

Posisi (1) lycra selaku benang inti berada pada pinggir perputaran benang dan serat kapas membungkusnya dengan sempurna. Didapat posisi ideal dimana benang inti berada di tengah, sehingga kapas membungkusnya dengan baik ke arah sebelah kanan (twist Z). Secara visual di dapat benang itu akan tergintir dan menyatu dengan baik.

\section{POSISI 2}

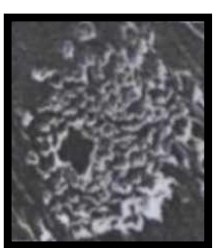

Pada posisi (2) didapat filamen lycra selaku benang inti berada pada tengah perputaran benang, sehingga apabila twist terbentuk ke arah kanan, maka benang itu dapat dikatakan pecah, dimana antara kedua serat tidak teruntai dengan baik.

\section{POSISI 3}

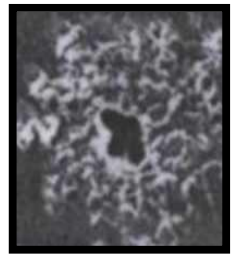

Pada posisi (3) didapat filamen lycra selaku benang inti berada pada diantara posisi pinggir dan tengah dari perputaran, dapat dilihat secara visual maka pada benang tersebut akan dapat dikatakan pecah

\section{PENGUJIAN DAN PEMBAHASAN}

\subsection{Pemilihan Bahan Baku}

Bahan baku untuk proses pembuatan benang elastan adalah, kapas combed sendiri dan filamen lycra yang merupakan nama dagang dari du pont. Untuk kapas sendiri bahan baku pada proses ring frame adalah roving. Yang berasal dari mesin flyer pada lot ke-8, dengan kondisi suhu $(27 \pm 1)^{\circ} \mathrm{C}$ dan $\mathrm{RH}(56 \pm 2) \%$

Percobaan yang dilakukan penulis dilakukan pada mesin ring frame dengan no mesin 40, terletak pada line ke-2, pada unit spining $\mathrm{V}$ pada PT Apac Inti Corpora. Dengan kondisi mesin tersebut berfungsi memproduksi benang elastan CmSy 10/40, dengan spesifikasi sebagai berikut: 
1. Jenis Mesin

- Merek

- Buatan

- Tahun

- RPM

- Jumlah Spindle

- Count

- TPI/Lot

- Ne Roving

- Ring.Flange

- Dimensi

2. Jenis Alat Tambahan

- Merek

- Buatan

- Tahun

- Variasi Draft
Ring Frame

Shanghai FA-503

China

1992

6000

480 spindle

CmSy 10/40 DLW

12.0 / V8

0.62 atau $9.5 / 10 \mathrm{~m}$

45

$16520 \times 620 \times 2338$

$\checkmark$ groove

Pinter SA

Spanyol

1997

$26,24,22,20$

\subsection{Persiapan Pengambilan Sample}

Pengambilan sample uji dalam percobaan ini direncanakan dengan prosedur di bawah :

1. Dengan tiga perlakuan, terhadap settingan jatuhnya posisi filamen pada roving, maka direncanakan pengambilan sample sebanyak 10 spindle (bobbin), terhadap 10 populasi yang ada pada tiap setting posisi.

2. membedakan warna bobin pada tiap variasi; warna hijau untuk posisi 1 , warna merah untuk posisi 2, dan warna biru untuk posisi 3. Dengan total bobbin sebanyak 30 buah, dengan 3 warna berbeda.

3. Menentukan nomor spindle yang dipakai, yaitu nomor spindle 1 sampai dengan 10 pada mesin tersebut.

4. Percobaan dilakukan dengan durasi waktu 1 jam 45 menit, dalam satu kali doffing, sebanyak 10 bobin tiap setting posisi.

5. Setelah itu dilakukan pengujian kekuatan benang

\subsection{Setting Penghantar Filamen}

1. Pastikan agar adanya kesamaan setting antara, penghantar filamen dan penghantar roving.

2. Atur jatuhnya posisi filamen pada roving, sesuai dengan variasi posisi yang akan dicoba. Caranya kendorkan baut pada tension dengan mempergunakan kunci L (ukuran 2.5).

3. Kencangkan baut pada tension dengan kunci $L$ (ukuran2.5), setelah mendapatkan posisi yang sesuai. Dimana fungsi tension tersebut berfungsi menjaga tegangan filamen, yang jatuh di atas top front roll.

4. Untuk menjaganya agar tetap pada posisi tertentu, lakukan pengecekan ulang dalam durasi waktu tertentu. 


\subsection{Hasil Pengamatan}

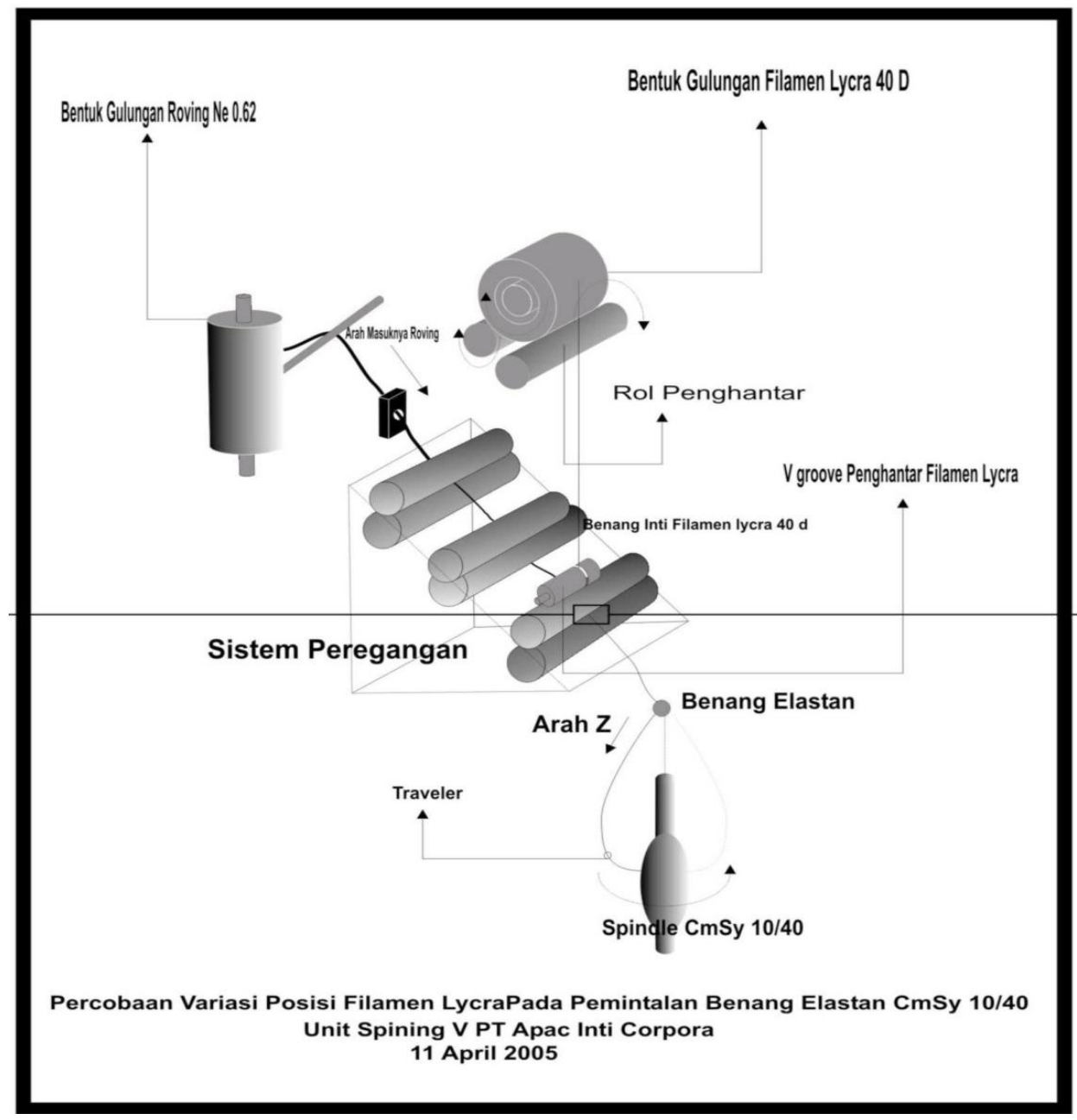

Gambar 2.1 Percobaan Pembuatan Benang Elastan Cmsy10/40d

Dari percobaan yang dilakukan penulis, maka dijabarkan oleh penulis sebagai berikut :

1. Roving combed Ne. 0.62 dihantarkan oleh kondensor (dalam keadaan tidak bergerak) sebelum mengalami peregangan pada; back roll, middle rol,dan front roll (sistem peregangan). (gambar 3.2)

2. Filamen Lycra $40 \mathrm{D}$ sendiri dihantarkan oleh rol penghantar filamen $v$ groove langsung menuju front roll (dengan setting posisi tertentu). (gambar 3.2)

3. Terbentuknya benang elastan pada front roll merupakan proses penggabungan kedua serat tersebut. (gambar 3.2) 
4. Setting posisi pada filamen pada front roll dapat dilihat pada gambar 3.3, dimana terlihat variasi posisi $(1,2,3)$ filamen lycra.

5. Lalu setelah terjadinya penggabungan roving dan filamen, maka terjadilah pergintiran ke arah $\mathbf{Z}$.

6. Benang Elastan tersebut di gulung dalam bentuk bobbin.

7. Dari hasil benang tersebut kita dapat melihat variasi posisi secara visual, dengan cara memuntir benang tersebut.(gambar 3.4) .
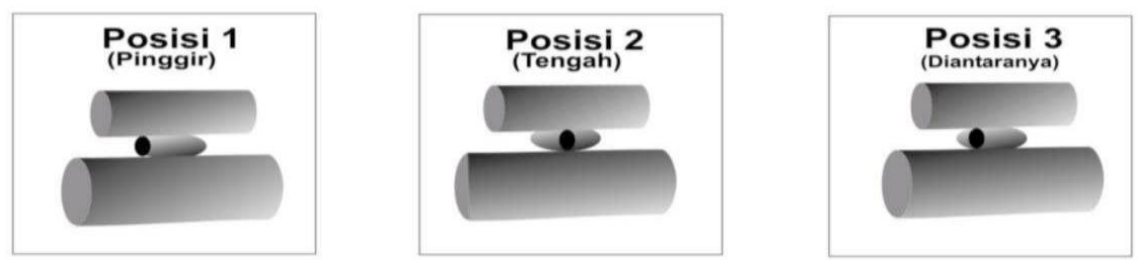

Variasi Posisi Filamen Lycra 40 D Terhadap Roving Ne 0.62 Pada Pemintalan Benang Elastan CmSy $10 / 40$ Unit Spining V PT Apac Inti Corpora

Gambar 2.3 Variasi Posisi Pada Percobaan Benang Elastan Cmsy 10/40 D

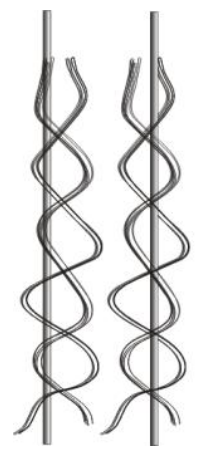

(1)

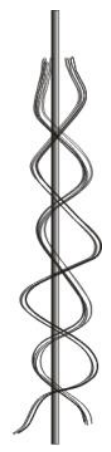

(3)

Gambar 2.4 Visual Benang Elastan Pada Posisi (1),(2),(3)

\subsection{Pengolahan Data}

\section{Pengaruh Posisi Filamen Terhadap Kekuatan Tarik Benang (RKM).}

Dari hasil percobaan yang dilakukan didapat berbagai macam bahan dapat didiskusikan, dengan hasil data sebagai berikut :

1. Statistik Metode Analisa Deskriptif Frekuensi 
Tabel 2.1 Data Hasil Uji Kekuatan Tarik Benang (Kg Nm)

\begin{tabular}{|c|c|c|c|}
\hline \multirow{2}{*}{ No. } & \multicolumn{3}{|c|}{ POSISI } \\
\cline { 2 - 4 } & 1 & 2 & 3 \\
\hline 1 & 17.93 & 15.49 & 16.37 \\
\hline 2 & 17.80 & 17.38 & 16.67 \\
\hline 3 & 16.87 & 15.54 & 16.61 \\
\hline 4 & 17.25 & 16.22 & 16.21 \\
\hline 5 & 16.44 & 16.80 & 17.62 \\
\hline 6 & 17.99 & 18.24 & 17.49 \\
\hline 7 & 17.78 & 12.92 & 17.07 \\
\hline 8 & 17.35 & 16.48 & 17.28 \\
\hline 9 & 16.91 & 13.98 & 19.24 \\
\hline 10 & 18.67 & 17.65 & 17.60 \\
\hline $\mathrm{X}$ & 17.4950 & 16.1700 & 17.2160 \\
\hline SD & 0.6596 & 1.651 & 0.8756 \\
\hline CV & 3.770 & 10.210 & 5.085 \\
\hline
\end{tabular}

2. Uji anova

Berdasarkan hasil pengamatan dan pengolahan data percobaan yang telah dilakukan penulis. dengan perlakuan posisi 1 (pinggir), posisi 2 (tengah) dan posisi 3 (diantaranya) berpengaruh pada kekuatan tarik benang elastan.

Dengan hipotesis :

Ho : Rata - rata ketiga variable tidak identik

Ha : Rata - rata ketiga variable identik pada RKM

Kriteria :

$\mathrm{HO}$ : Ditolak jika; sig $<\alpha$

sig

$$
\begin{aligned}
& =0.023 \\
& =0.05
\end{aligned}
$$

Dari ketiga variable diatas hanya RKM yang memiliki sig $<\alpha$

Maka Ho : Ditolak

Maka Ha : Diterima

Jadi kesimpulannya : Rata - rata ketiga variable identik (dapat dilanjutkan ke analisa tukey).

Dengan hipotesis tukey selanjutnya

Ho : Tidak ada pengaruh posisi pada kekuatan (RKM)

$\mathrm{Ha}$ : Ada pengaruh posisi pada kekuatan (RKM)

Dengan hasil kriteria sebagai berikut :

Posisi 1 (pinggir), sig = 0,025

Posisi 2 (tengah), sig $=0,083$

Posisi 3 (diantaranya) sig $=0,025$ 
Dari ketiga variable diatas hanya Posisi Pinggir danTepi yang RKM nya memiliki $\operatorname{sig}<\alpha$

$\begin{array}{ll}\text { Maka Ho } & \text { : Ditolak } \\ \text { Maka Ha } & \text { : Diterima }\end{array}$

Ada pengaruh posisi pada kekuatan (RKM) Tetapi hanya pada posisi pinggir dan diantaranya.

Setelah menggunakan metode anova untuk membandingkan lebih dari dua variable, maka digunakan kembali uji perbandingan dua variable antara posisi 1 (pinggir) dan posisi 3 (diantaranya) dengan menggunakan t test.

Hipotesis

Ho : Varian posisi $1=$ varian posisi 3

$\mathrm{Ha} \quad$ : Varian posisi $1 \neq$ varian posisi 3

Kriteria :

$\mathrm{HO}$ : Ditolak jika; sig $<\alpha$

sig $\quad=0.036$

$\alpha \quad=0.05$

Maka Ho : Ditolak

Maka Ha : Diterima

Jadi kesimpulannya $\mathrm{Ha}$ : Varian posisi $1 \neq$ varian posisi 3

Uji selisih Rata-rata

Hipotesis

Ho : Rata-rata posisi 1 = rata-rata posisi 3

$\mathrm{Ha} \quad$ : Rata-rata posisi $1 \neq$ rata-rata posisi 3

Kriteria :

$\mathrm{HO}$ : Ditolak jika; sig $<\alpha$

sig $\quad=0.020$

$\alpha \quad=0.05$

Maka Ho : Ditolak

Maka Ha : Diterima

Jadi kesimpulannya $\mathrm{Ha}$ : Rata-rata posisi $1 \neq$ rata-rata posisi 3

Maka dapat disimpulkan bahwa posisi 1 (pinggir) paling baik mempengaruhi RKM (kekuatan tarik).

\subsection{Pengaruh Posisi Filamen Terhadap Mulur Benang.}

Dari hasil percobaan yang dilakukan didapat berbagai macam bahan dapat didiskusikan, dengan hasil data sebagai berikut :

1. Statistik Metode Analisa Deskriptif Frekuensi 
Tabel 2.2 Data Hasil Uji Mulur (\%)

\begin{tabular}{|c|c|c|c|}
\hline \multirow{2}{*}{ No. } & \multicolumn{3}{|c|}{ POSISI } \\
\cline { 2 - 4 } & 1 & 2 & 3 \\
\hline 1 & 8.30 & 7.68 & 7.40 \\
\hline 2 & 8.55 & 7.91 & 8.36 \\
\hline 3 & 8.17 & 7.75 & 6.81 \\
\hline 4 & 8.16 & 7.28 & 7.84 \\
\hline 5 & 7.97 & 8.12 & 8.42 \\
\hline 6 & 8.30 & 7.86 & 8.93 \\
\hline 7 & 7.65 & 8.38 & 8.36 \\
\hline 8 & 8.23 & 8.03 & 7.66 \\
\hline 9 & 8.10 & 8.11 & 7.65 \\
\hline 10 & 8.41 & 7.85 & 8.36 \\
\hline$X$ & 8.8140 & 7.8970 & 7.9790 \\
\hline SD & 0.2978 & 0.2980 & 0.6205 \\
\hline CV & 2.378 & 3.773 & 7.776 \\
\hline
\end{tabular}

\section{Uji anova}

Hipotesis

Ho : Rata - rata ketiga variable tidak identik

$\mathrm{Ha}$ : Rata - rata ketiga variable identik

Kriteria :

\section{H0 : Ditolak jika; sig $<\alpha$}

sig

$$
\begin{aligned}
& =0.310 \\
& =0.05
\end{aligned}
$$

Dari ketiga variable diatas hanya RKM yang memiliki sig $<\alpha$
Maka Ho
Diterima
Maka Ha
Ditolak

Jadi kesimpulannya : Rata - rata ketiga variable tidak identik

Maka dapat disimpulkan Elongation tidak dapat memenuhi pengolahan data

selanjutnya, dikarenakan rata-rata variable tidak identik.

\section{Kesimpulan}

1. Perbedaan posisi elastomer pada front roll terhadap arah twist benang pembungkus menunjukkan rata-rata kekuatan tarik yang identik. Dengan pengolahan data lebih lanjut, percobaan pada posisi 1 (elastomer berada di pinggir) menghasilkan kekuatan tarik yang paling besar, yaitu $17,4950 \mathrm{KgNm}$. Hal ini dikarenakan kedudukan benang lycra (elastomer) sebagai benang inti berada di tengah dan terbungkus dengan baik karena mampu tergintir dengan sempurna oleh benang kapas. Sehingga disimpulkan posisi (1) menghasilkan kekuatan dan mulur yang paling ideal.

2. Perbedaan posisi elastomer pada front roll terhadap arah twist benang pembungkus tidak menunjukkan rata-rata mulur yang identik. Dapat terlihat bahwa percobaan 1 (elastomer berada di pinggir) menghasilkan 
mulur yang paling tinggi, yaitu sebesesar $8.8140 \%$. Susunan benang yang dihasilkan oleh percobaan 1 lebih compact. Ketika elastomer mampu tergintir dengan sempurna oleh serat kapas, maka persentase mulur pun akan bertambah.

3. Persentase mulur benang elastan berbanding lurus dengan kekuatan tariknya. Semakin tinggi kekuatan tarik, maka persentase mulur akan semakin tinggi.

\section{DAFTAR PUSTAKA}

\section{Buku :}

1. Pawitro, Soemarno, Hartono, Suparmas, Teknologi Pemintalan Bagian Pertama, Institut Teknologi Tekstil, Bandung, 1973.

2. Pawitro, Soemarno, Hartono, Suparmas, Teknologi Pemintalan Bagian Kedua, Institut Teknologi Tekstil, Bandung, 1975.

3. P.Suprjiono, Serat-Serat Tekstil, Institut Teknologi Bandung, 1973.

$4 . \quad$ Instruksi Kerja Laborat, PT Apac Inti Corpora.

$5 . \longrightarrow$ Model FA 503 Ring Spinning Frames Instruction Manual (FA 503), Shanghai No. 2 Textile Machinery Works, The People Republic of China.

6. Manual Handbook of Pinter SA.

7. Sugiyono, Statistika Untuk Penelitian, CV Alfabeta, Bandung, 2005.

8. Wibowo Moerdoko, Isminingsih, Wagimun, Soeripto, Evaluasi Tekstil Bagian Fisika, InstitutTeknologi Tekstil, Bandung, 1973.

\section{Website dan Email :}

1. http//www. dupont.com

2. http//www.findarticles.com/textile research journal.

3. Ir. Reda Rizal, M.Si., Teknologi Pembuatan Benang Elastan (Lycra).

\section{Artikel \& Jurnal :}

1. A. P. S. Sawhney, G. F. Ruppenicker, L. B. Kimmel, and K. Q. Robert, Comparison of Filament-Core Spun Yarns Produced by New and Conventional Methods, New Orleans, Louisiana, U.S.A.

2. A. P. S. Sawhney, G. F. Ruppenicker, L. B. Kimmel, and K. Q. Robert, Improved Method of Producing a Cotton / Polyester Staple-Core Yarn on Ring Spinning Frame, New Orleans, Louisiana, U.S.A.

3. Ching-luan Su and Hsiao-Ying Yang, Structure and Elasticity of Fine Alastomeric Yarns, Taipei, Taiwan, Republic of China.

4. Ching-luan Su, Meei-Chyi Maa, and Hsiao-Ying Yang, Structure and Performance of Elastic Core-Spun Yarn, Taipei, Taiwan, Republic of China.

5. Osman Baarslan, Method of Producing a Polyester / Viscose Core-Spun Yarn Containing Lycra Using a Modified Ring Spinning Frame, BalcaliAdana, Turkey. 